\title{
ORGANISATIONAL RESPONSES TO DISCONTINUOUS INNOVATION: A CASE STUDY APPROACH
}

\author{
JEFFREY T. MACHER \\ McDonough School of Business, Georgetown University \\ Washington, DC 20057, USA \\ jtm4@georgetown.edu \\ BARAK D. RICHMAN \\ Duke University School of Law \\ Box 90360, Durham, NC 27708-0360, USA \\ richman@law.duke.edu
}

Received 29 July 2003

Revised 24 December 2003

Accepted 5 January 2004

\begin{abstract}
Research that examines entrant-incumbent dynamics often points to the organisational limitations that constrain incumbents from successfully pursuing new technologies or fending off new entrants. Some incumbents are nevertheless able to successfully implement organisational structures and develop routines that overcome these institutional constraints. We provide a case-study analysis of how three firms - Motorola, IBM and Kodak responded to "discontinuous" innovations and the associated structural and organisational limitations that are typical to incumbent organisations. Each firm was able to capture gains from new technologies and develop profitable products in emerging markets, although their abilities to sustain these gains varied due to subsequent organisational changes. Drawing from these case studies, we synthesise how firms can institute organisational strategies to continue to capture gains from disruptive innovations. A schema suggests that particular organisational strategies are comparatively optimal for corresponding points along an innovation lifecycle.
\end{abstract}

Keywords: Architectural/radical innovation; entrant-incumbent competition; management of technology.

\section{Introduction}

Technological change often pits entrant firms against well-established incumbent firms for market and technological leadership. In the literature that explores this 
dynamic, researchers point to the declining performance of incumbents in the face of radical (Abernathy and Utterback, 1978; Cooper and Schendel, 1976) and architectural (Henderson and Clark, 1990) innovation. Entrants win the majority of these technological battles despite incumbents' obvious advantages in resources, experience, and other important factors (Teece, 1986). The persistent failures of incumbents have led some scholars to emphasise the roles that organisational inertia (Hannan and Freeman, 1984), highly structured routines (Nelson and Winter, 1982) and absorptive capacity (Cohen and Levinthal, 1990) play in constraining the actions and ultimate success of incumbents. Thoughtful (and related) frameworks have been developed that explain how and why incumbent leadership under one technological paradigm does not always translate into and in some cases is a detriment for - success in subsequent paradigms (Anderson and Tushman, 1990; Henderson and Clark, 1990). By contrast, the observable repeated success of market entrants has led others to articulate an attacker's advantage (Christensen and Rosenbloom, 1995; Foster, 1986). In this approach, entrant firms are argued better suited than incumbent firms to developing and commercialising emerging technologies because of their smaller size, shorter (path-dependent) histories, and more limited commitments to value networks and current technological paradigms.

Although the innovation literature has made significant progress in explaining why incumbent firms face greater difficulties adjusting to "discontinuous" innovations, and correspondingly, why entrant firms face these difficulties to a lesser extent, far less is known how certain incumbent firms have been able to buck this pattern. To be sure, some incumbent firms have successfully adapted and responded to discontinuous innovations, and either recaptured their previous market or technological positions or remained the de facto leaders (Ahuja and Lampert, 2001; Hill and Rothaermel, 2003; Methe et al., 1997; Rosenbloom and Christensen, 1998; Rothaermel, 2001). This paper adds to this research stream by investigating how incumbent firms have successfully responded to technological discontinuities and have maintained leadership after the introduction of these new technologies via their implementation of particular organisational approaches. We analyse these incumbent "success stories" through detailed examinations of three case studies, which delineate the organisational approaches that incumbent firms took in responding to the emergence of "discontinuous" innovations that had the potential to unseat their market and technological leadership positions. By discontinuous innovation, we refer to those innovations that generate market and/or technological discontinuities and subsequently affect incumbent firms' abilities to adapt and respond to these changes.

In our approach, we build upon organisational theory explanations (Cohen and Levinthal, 1990; Hannan and Freeman, 1984; Nelson and Winter, 1982) of 
incumbent failure and entrant-incumbent models (Christensen, 1997; Christensen and Rosenbloom, 1995; Henderson and Clark, 1990; Tushman and Anderson, 1986) to articulate how some incumbent firms are able to survive the emergence of radical and architectural innovations. The significance of our approach lies in our identification of particular organisational strategies that were implemented by firms in different industries that confronted technological threats. Since the above theoretical models and frameworks have seen more limited application in explaining incumbent success stories, the findings from our case studies illustrate some new and potential applications.

This paper is neither an attempt to generalise how incumbent firms respond to discontinuous innovation nor an offering of normative prescriptions (Hill and Rothaermel, 2003). Our research objective instead is to uncover and explicate how incumbent firms respond to discontinuous innovations through different organisational strategies and approaches. In each of our case studies, firms recognised that well-established organisational structures and routines designed for familiar technological paradigms were ineffective in - and even served as barriers to - developing and commercialising new technologies. In pursuing these new technologies, the firms instead implemented new organisational entities (described below) that supplemented and improved upon their existing routines and knowledge bases. The firms also recognised the need and the importance of reorganising internally, but, notably and importantly, different approaches were taken. While three success stories are not sufficient to construct far-reaching conclusions, the case studies are instructive in identifying and characterising particular organisational responses to discontinuous innovations.

The remainder of this paper is organised as follows. The next section reviews innovation literature on innovation typologies and entrant-incumbent dynamics, displacement and performance. Three case studies are then presented to illustrate how particular incumbent firms pursued creative and novel organisational strategies to respond to technological discontinuities, maintain their industry leadership, and in some cases, capture additional profits brought on by these new technologies. We briefly review Motorola's success in developing cellular telephone technology, IBM's development of the personal computer (PC), and Kodak's struggles to develop digital imaging technology, respectively. The subsequent section draws out the commonalities among the different organisational strategies employed by the firms in the case studies presented and introduces a schema that suggests how various stages in the innovation cycle influences these strategic decisions. We then review the lessons learned and articulate areas of further research. The final section concludes. 


\section{Theoretical Background}

Our central focus is examining the organisational approaches taken by incumbent firms in response to "discontinuous innovations", or those innovations that generate market and/or technological discontinuities. These kinds of innovations affect the abilities of incumbent firms to successfully adapt and respond, as well as to sustain their prior market and technological positions. The literature generally categorises discontinuous innovation as either radical or architectural in nature. Radical innovation requires knowledge that is usually based on engineering and scientific principles that are unfamiliar to incumbent firms. While such innovation opens up new markets, it also requires new and different technical and commercial skills and new problem-solving approaches that often do not exist in or are difficult to develop by incumbent firms. Architectural innovation is the way in which the components of a product offering are linked together. While leaving the core design concepts untouched, architectural innovation reconfigures established "systems" in new and (potentially) novel ways and thus potentially destroys the usefulness of firms' existing architectural knowledge. Both radical and architectural innovation are argued difficult for incumbent firms to adapt and respond to because the knowledge and skill sets required are not resident in the organisation (Henderson and Clark, 1990). Discontinuous innovation unsurprisingly contrasts with "incremental innovation" or "sustaining innovation", which typically introduces relatively minor changes to existing products, exploits the potential of established designs, and reinforces the dominance and capabilities of incumbent firms.

Incumbent firm challenges associated with maintaining competitive advantage typically involve responding to innovation streams and technology cycles. Abernathy and Utterback (1978) and Anderson and Tushman (Anderson and Tushman, 1990; Tushman and Anderson, 1986) laid the foundations to such a model, whereby innovation results in alternating periods of technological variation, selection and retention. In this approach, different potential technological approaches lead to discontinuities that trigger periods of technological and competitive ferment. This "era of ferment" produces significant technological variation and competition by incumbent and entrant firms in the technology space. Eventually, the winning technology is "selected" by the market and becomes the industry standard or dominant design. Dominant designs, though normally initiated by competitive interaction, tend not to be technologically driven, but rather emerge out of competition between alternative technological approaches that are pushed by competitors, alliance groups, and government regulators. The new dominant design is retained throughout the subsequent "era of incremental change", which persists longer than the era of ferment and in which innovation 
shifts from radical in nature to more incremental and from product-oriented to process-oriented. ${ }^{1}$ The era of incremental innovation is characterised by relatively stable markets, established industry leaders (incumbents), and a pervasive technological paradigm embodied in a single dominant design. Not surprisingly, incumbent firms in this era are advantaged because their structured routines are characterised by reliability, predictability, and accountability (Nelson and Winter, 1982).

This stable organisational approach gives way, however, when a technological discontinuity is introduced and gives rise to another era of ferment. The new technological possibilities unleash a rush by both entrant and incumbent firms to introduce new products and processes that aim to capture profits from the emerging technology paradigm. The unwieldy scrum that denotes the era of ferment is one of high uncertainty, intense radical and/or architectural innovation, and rapid technological change. Firms must accordingly develop more flexible and dynamic approaches in these environments, which contrast sharply to the stable and predictable approaches that prove beneficial during the era of incremental change (Thomke and Reinertsen, 1998; Tushman and O'Reilly, 1996).

This foundational literature advances three important claims regarding how firms compete in technological innovation and how entrant-incumbent dynamics evolve. First, innovation evolves through separate and punctuated phases that present distinct technological and competitive demands. Second, firm routines and organisational approaches that are successful in one technology paradigm do not necessarily translate into success in subsequent and other paradigms. Third, discontinuous innovations are usually pioneered and commercialised by entrant firms, which typically displace incumbent firms. We expand upon each of these claims below.

Organisational theorists have emphasised the roles that organisational inertia (Hannan and Freeman, 1984), structured routines (Nelson and Winter, 1982), and absorptive capacity (Cohen and Levinthal, 1990) play in constraining the actions and limiting the success of incumbent firms. Organisational inertia constrains the abilities of incumbent firms because the structures and systems that facilitate survival in stable and predictable environments become liabilities in environments undergoing rapid change (Amburgey et al., 1993; Hannan and Freeman, 1984).

\footnotetext{
${ }^{1}$ Pisano (1997), however, would challenge the argument that innovation moves from product to process with the emergence of a dominant design. In many so-called process-enabling industries, product innovation and process innovation often are hand-in-glove. Examples of these industries include pharmaceuticals/biotechnology, specialty chemicals, advanced materials, and high-precision miniature electronic goods.
} 
A similar and related literature argues that organisations develop highly structured routines in order to reduce the costs associated with information acquisition (Nelson and Winter, 1982). These routines operate well in stable and predictable environments, but over time or in turbulent environments these same routines limit firms' capacities to selectively search and acquire knowledge (Levitt and March, 1988). As organisations begin to focus their routines around the functions or competencies that represent past success, they neglect most other, and potentially important, technological areas (Miller, 1993). In short, core competencies become core rigidities (Leonard-Barton, 1992). Additionally, an inability to "recognise the value of new information, assimilate it, and apply it to commercial ends" (Cohen and Levinthal, 1990: 128) also has been argued as a reason incumbent firms have difficulties responding to discontinuous innovations. Because the "absorptive capacity" of firms is built upon prior and related knowledge, and because discontinuous innovations generally require knowledge that exists outside of the firm, incumbent firms are unable to recognise and fully embrace new technological paradigms.

A closely related literature argues that the business competencies that support incumbent firms' success during one technological paradigm may in fact deter incumbent firms from succeeding in subsequent paradigms (Foster, 1986). Henderson and Clark (1990) and Christensen and Rosenbloom (1995) provide support for this framework by offering specific mechanisms that articulate how this process occurs. Firm competencies evolve to establish filters and information channels that create valuable efficiencies during certain technological paradigms, but these same competencies can also serve as blinders that prevent firms from appreciating or understanding the emergence of new technologies. Consequently, the emergence of discontinuous innovations that require new structural relationships create difficulties for organisations that have well established routines based in earlier technological paradigms.

These theories and frameworks generally make strong arguments that incumbent firms' organisational approaches and routines support success in one technological paradigm but may represent barriers and challenges to developing the necessary routines and competencies to compete successfully in new technological arenas. By contrast, entrant firms do not face the same challenges, or do so to a lesser extent, than incumbent firms. Entrant firms have more muted forces of internal inertia, either because of their smaller size and more limited path-dependent histories. Entrant firms also do not have the same levels of commitment to current suppliers and customers (i.e., their value network) or to current technologies (Christensen and Rosenbloom, 1995). These firms can thus more readily focus on smaller market and technological niches with potentially greater growth potential, albeit with greater risk. Not surprisingly, the empirical literature has 
generally found that new and discontinuous innovations are developed and commercialised by new entrants (Abernathy and Utterback, 1978; Anderson and Tushman, 1990; Christensen, 1997; Cooper and Schendel, 1976; Dosi, 1988; Foster, 1986; Henderson and Clark, 1990; Tushman and Anderson, 1986).

Despite the myriad examples of incumbent firm failures and entrant firm successes, there are several counterexamples that have been articulated in the literature (Ahuja and Lampert, 2001; Methe et al., 1997; Rosenbloom and Christensen, 1998; Rothaermel, 2001). These studies demonstrate that some incumbent firms have successfully adapted and responded to discontinuous innovations, either recapturing their previous positions or remaining the market or technological leaders. Because these counterexamples exist, the research question importantly becomes how certain incumbent firms who enjoy market and technological leadership through periods of incremental innovation can simultaneously respond to the challenges of discontinuous innovation. Although many factors and approaches are important (Hill and Rothaermel, 2003), we argue that the organisational approaches that incumbent firms take in responding to the emergence of discontinuous innovations play a central role.

The firms in the three case studies discussed below encountered similar discontinuous innovations, and each responded with similar organisational strategies. Managers within each organisation concluded that the current structures and routines in place could not succeed in the new technological paradigm, and their firms consequently would not sustain industry leadership if they remained burdened with the existing structures and routines designed for stable and incremental innovation. Each organisation instead developed new structures and routines that were specific to and targeted at the demands of the emerging technological paradigm.

\section{Empirical Analysis}

\section{Alternative organisational approaches}

In each of the case studies that we examine, organisations were confronted with similar problems in the emergence of a new discontinuous innovation that threatened a core part of their business. The existing organisational structures and routines in place were ineffective in developing profitable products for these emerging technologies. Each of the incumbent firms responded by implementing new organisational entities that differed substantially from these prior entities. Despite this commonality, the case studies reveal that a spectrum of organisational strategies and approaches were undertaken. More importantly, each organisation was able to develop and implement new structures and routines that met the 
requirements of the discontinuous innovation head-on. Before describing the individual case studies in detail, we briefly define and describe three different organisational approaches that were employed by the firms in the case studies: internal ventures, joint ventures, and acquisitions (Roberts and Berry, 1985).

An internal venture is a structure in which an organisation develops and implements a set of routines and practices that are different and separate from the core set of operations. The internal venture may or may not constitute a separate division or separate project that is organisationally or geographically separate from the rest of the firm, but it is unique in that it has objectives that are largely independent from, and in some senses counter to, the rest of the firm. ${ }^{2}$ As new technologies develop within the separate venture, distinct routines often emerge within it that support the new technological paradigm and the development and commercialisation of new product offerings. These routines are usually distinct from the current routines within the existing organisation in that they are specifically targeted toward developing and commercialising the new technology.

When firms are unable or unwilling to develop new technologies on their own, they often turn to outside entities and form joint ventures. ${ }^{3}$ A joint venture is a new organisational relationship with a partner or partner firms that allows the focal firm to gain access to its partner's knowledge and capabilities (Kogut, 1988). The conjoined firms can then develop and commercialise new technologies for new product offerings, leveraging the unique skill sets that each brings to the table. As the joint venture advances and the organisational relationships solidify, new routines evolve specifically to support the interfirm arrangement's underlying technology goals and product development objectives. These new routines can remain separate from both firms' pre-venture routines and can be utilised to develop new products for emerging technological paradigms.

If a firm is unable to execute a technology strategy - either on its own or with partner firms - to accommodate to an emerging discontinuous innovation, it may elect to acquire separate companies that have already begun to develop or commercialise products under the new technological paradigm. When it makes such an acquisition, the focal firm normally gains access both to new technologies

\footnotetext{
${ }^{2}$ For example, some of these internal ventures are charged with the responsibility of developing products that will cannibalise the organisation's current sales. Some managers will obviously perceive their personal interests to be inconsistent with the aims of such a venture.

${ }^{3}$ While "Joint Venture" has a particular legal definition, the term used here is purely economic. For the purposes of this paper, a joint venture represents any endeavor by two or more firms to develop a certain technology that reaches beyond each firm's standard bundles of routines. Of course, this use of "joint venture" includes many forms of legally incorporated joint ventures.
} 
and to the underlying routines and skill sets that support those technologies. Unlike internal ventures and joint ventures, the acquired company is normally more viable in terms of its technological or product market offerings with routines already designed for the new paradigm.

\section{Case studies methodology}

The case studies examined below illustrate how three different organisations employed a combination of internal ventures, joint venture creation, and acquisitions of other companies. These three firms - Motorola, IBM, and Kodak - were not chosen at random. Rather, we targeted large firms that not only have enjoyed long-standing leadership in innovation-intensive industries, but also for which interviews with either current or former high-level managers were feasible. As Motorola, IBM, and Kodak met those restrictive criteria, no other firms were targeted for analysis. Since our interest focused on corporate strategy development and the implementation challenges that confront managers, we solely interviewed high-level managers who played substantial roles in devising corporate strategy and had authority to initiate large-scale projects. We then supplemented the information attained from the interviews with other publicly available, firmspecific research. Lastly, we sent advanced copies of a draft of this paper to the managers we interviewed and asked them to confirm the veracity of our accounts. All the interviewees responded and offered only minor corrections. We thus feel comfortable with the accuracy of our case studies.

While the firms were selected with deliberateness, the case studies were not. We began all of our field research interviews with general open-ended questions, asking managers how their organisation has coped with the challenges posed, and the lucrative potential offered, by new technologies and discontinuous innovations. The generalisations that form the core of this paper emerged only after we detected distinct similarities in the answers we received. Each firm boasted certain management successes, and those success stories exhibited valuable parallels. Our field interviews also discussed several technological threats not discussed here, and a vast majority of those threats and opportunities were not followed by successful organisational responses. The field interviews suggested that the sources of those failures also had common roots.

Our methodologies and research approach resemble those employed by Dougherty (1992) and Dougherty and others (1996; 1994), but there are some important differences. First, our focus is on top-down management and the directional challenges that confront high-level managers, whereas this earlier research interviewed more mid-level managers and explored the broader institutional features of large firms in innovation-intensive industries. Second, we 
limit our discussion to, and find many valuable lessons in, each organisation's success stories, whereas this earlier research mainly explored the difficulties and barriers to success in the daily operation of firms. Our research project also involves fewer interviews and fewer innovative projects than the earlier work with a larger-scale focus. While our project embodies many of the same questions and methodologies as these other valuable contributions, we believe our conclusions constitute notable contributions that those and other works have not yet adequately explored. Consequently, our approach is a useful complement to research that seeks to understand incumbent firms' successes and failures and managers' challenges and opportunities. We discuss each case study in turn.

\section{Motorola - Internal ventures and the cannibalisation of a successful product}

Since 1930, when the company introduced the first practical and affordable auto radio, and through the 1960s, when it supplied communication equipment for NASA's moon landings, Motorola dominated both the high-end and consumer markets for communications equipment, especially in wireless technology. Motorola was a clear leader in communications technology in the 1970s, and the communications division enjoyed growing annual sales every year from 1951 through $1975 .^{4}$

Nevertheless, executives leading Motorola's research in wireless communications technology foresaw possibilities to improve its consumer lines in mobile telephones. Into the 1970s, Motorola offered consumers bulky mobile products at $400 \mathrm{MHz}$, an inefficient technology at the time. Jim Mikulski, who worked in Motorola's corporate research division, observed that an assortment of emerging technologies had created new commercial opportunities. Most notably, complex and inexpensive integrated circuits were available for diverse applications, $\mathrm{rf}$ power devices became increasingly efficient and inexpensive, and new communications systems hinted at new technological paradigms. Mikulski envisioned a radically new cellular technology that could replace the existing capacity-limited MTS system. ${ }^{5}$ The new mobile phone products based on these technological advancements would be high-capacity radiotelephones that operated

\footnotetext{
${ }^{4}$ See Motorola web page at http://www.motorola.com/content/0,,115-110,00.html.

${ }^{5}$ The seminal patent for cellular technology actually came from Bell Labs in the early 1950s as a solution to another problem. However, because the hardware to harness it for communication products did not yet exist, the idea lay fallow for twenty years. Mikulski is credited for first bringing the cellular technology to commercial uses.
} 
at higher frequencies utilising more powerful communication devices but would still be sufficiently inexpensive to ensure wide availability to various consumer segments.

In the late 1960s, Mikulski was confident his idea had commercial potential and approached John Mitchell, then Head of Motorola's Communications Division, requesting permission to develop the new cellular technology. Mitchell rejected Mikulski's proposal, arguing that $400 \mathrm{MHz}$ technology offered sufficient capacity and met consumer needs. The Communications Division current product line was the market leader, and a new product, which would likely cannibalise the current system, was deemed to be both unnecessary and potentially harmful to this business line.

Despite Mitchell's rejection, Mikulski remained determined to pursue the new system. He found support from Marty Cooper, director of Motorola's Corporate Research Laboratory, who had worked to develop the cellular technology throughout the late 1960s and early 1970s. Importantly, Cooper's sponsorship and Mitchell's rejection reflected an interesting feature of Motorola's corporate infrastructure. The company was primarily organised according to its product lines, where most strategic decisions regarding radio and mobile phones including the marketing of current phones and the development of new systems - were made by the communications division. Separated from the constituent divisions within Motorola stood the Corporate Division, which possessed some of its own research laboratories. While Mitchell was enmeshed within the routines committed to the company's current products, Cooper supervised research that could be less entangled within immediate product demands and more prospective towards new product lines.

Under Cooper's sponsorship, Mikulski assembled a research team hidden within the research branch of the Corporate Division and strategically isolated from Mitchell's Communications Division. It was there that he pioneered the development of the first generation of cellular phones. Later in the mid-1970s, when it became clear to industry observers that the $400 \mathrm{MHz}$ system was running into capacity constraints, Motorola's leadership saw an immediate need to advance radio communication. Recognising the inherent limitations, Mitchell agreed to pursue cellular technology. ${ }^{6}$ Mikulski then unveiled his new cellular system, which by that time had developed to an advanced stage and was poised for commercialisation.

\footnotetext{
${ }^{6}$ One rumored story related to us in our interviews recalls a day when Mitchell was unable to make a call on his own radio phone. The $400 \mathrm{MHz}$ technology and its limitations became readily apparent to him, and he shortly thereafter agreed to pursue the new technology and product development.
} 
The FCC granted licenses to Motorola and AT\&T in 1980 to commercialise cellular phones, and Motorola moved forward to introduce $800 \mathrm{MHz}$ products that lay the foundations to the AMPS system, the industry's dominant design. Motorola proceeded to reap generous profits from this introduction and its subsequent leadership in the cellular market. It enjoyed a 45 percent market share in the 1980s and a nearly 60 percent share in 1990. It was considered "one of the most admired companies in the world" by its competitors. ${ }^{7}$ Ironically, John Mitchell found similar good fortunes. Although initially opposed to pursuing new cellular technology, Mitchell shifted 180 degrees in the mid-1970s and became the $800 \mathrm{MHz}$ system's biggest champion, guiding the new system through FCC regulatory hurdles and ushering it into test markets by 1980. His strong support for the new technology, which was critical to the new products' success, helped bring him to the company's presidency in 1980.

Motorola's experience illustrates the challenges of organisational inertia (Hannan and Freeman, 1984) and the usefulness of a separate and internal venture that shields the development of new technologies from old-paradigm routines that are inherently hostile to such innovations. Despite the emerging possibilities in a superior technology, Motorola's key manager in the division responsible for new product development elected to stick with the current product generation, which could have undermined the development of new and potentially disruptive technologies. It would be easy to dismiss this decision as poor judgment, but the decision also reflects a level of routine embeddedness (Nelson and Winter, 1982) that is quite common to large and established organisations. Mitchell's early evaluation of the cellular project was based on established criteria that predictably forecasted demand, and these ritualised evaluations prejudiced him against cannibalising his own division's product. Sales were strong which brought accolades to his division, customer acquisition for new products was minimal, and change would certainly invite uncertainty. Not surprisingly, the decision to forego new technology development was guided by well-established routines that were specifically designed to filter information, emphasise organisational relationships between manufacturers and customers, and reduce uncertainty these routines were not designed to anticipate new technological applications or emerging markets (Cohen and Levinthal, 1990). Mitchell's perch atop the communications division thus biased him against the organisational change required to develop the new cellular system.

As an alternative organisational strategy, Mikulski and Cooper took a gamble on the new technology and sponsored a research team that was separate from the

${ }^{7}$ Steven Goldman quoted in "How Motorola Lost Its Way”. Business Week, 4 May 1998. p. 140. 
Communications Division. Here, the new product enjoyed a safe harbor and was able and given time to develop supporting routines that were explicitly designed for its individual needs. Subsequent routines and procedures to manufacture the new system were later incorporated into the communications division only after Mitchell and other executives were committed to the new design. Keeping the new operation initially separate from the existing division enabled Mikulski both to make appropriate investment decisions for the $800 \mathrm{MHz}$ system and to foster its development and eventual production.

Motorola's early experiences in the market for digital wireless phones, however, were far less successful. Unlike its success in cannibalising its earlier generation of wireless technology, Motorola remained committed to analog cellular products well after entrants introduced phones with the more advanced digital technology. Similar to the earlier struggle over cellular technology, some Motorola managers did notice the emergence of digital technology and urged the company to pursue commercialising digital cellular phones. ${ }^{8}$ Robert Weisshappel, chief of the Cellular Division, mimicked Mitchell's earlier faulty judgment and blocked these efforts. This time, however, no champion for the new digital technology rose to search for alternative organisational mechanisms to pursue it. Motorola subsequently lost its industry leadership in cellular systems, and saw its market share of the wireless phone market plummet to as low as 34 percent in 1997. Only after some successes in the late 1990s was it able to mount a comeback, though it remained a distant second in market share in the wireless market to Nokia. ${ }^{9}$

The sharp contrast between Motorola's success in advancing analog cellular phones and its failure to capture the market for digital products illustrates the difficulties associated with instituting organisational change. Dated routines, often embodied in dated judgment, are difficult barriers for any organisation to overcome. It is only through an inherent approach to continued innovation and learning and developing the requisite supporting routines for such innovation - can organisations overcome inertia. The key research insight in this case study therefore is Motorola's success in developing a new generation of cellular analog technology. The central lesson is that Motorola's Communication Division rested on routines that were unable or unwilling to develop products for a new technological paradigm, whereas the internal venture, which spanned boundaries internal to the

\footnotetext{
${ }^{8}$ Private interviews reveal that several managers within Motorola's corporate research division argued on behalf of digital technology, but the communications division decided to stick with its successful analog products.

${ }^{9}$ See Business Week. May 4, 1998 and "Motorola, Posting Big Profits, Rebounds from Troubles", New York Times, 18 January 2000, p. C16.
} 
firm, enjoyed a flexible infrastructure in which supporting routines could meet the unique needs of the new technological paradigm.

\section{IBM - Internal ventures, acquiring outside technology, and the $\mathrm{PC}$ experience}

In Frank Cary's last years as CEO of IBM, he watched the Apple personal computer (PC) usher in a new technological paradigm to the computing market. He sensed how important the new product would become and he instructed IBM's Computing Systems Division to design and commercialise a PC of its own. ${ }^{10}$ To Cary's frustration, the Computing Systems Division failed. Although it did manage to design a personal computer of high quality and engineering performance, the product exceeded common household computer needs and could not be sold at prices competitive with those of Apple. Cary charged the division to try several times again, but it repeatedly failed.

Exasperated, Jack Rogers, head of the division, suggested that IBM purchase Atari, a company with some relevant experience in low-cost computing. Cary scoffed at the idea indicating, "When you're the CEO of IBM, and you hear a suggestion to buy Atari, you know you have to change the way you do things". He knew IBM had the requisite technological skills in place to develop and manufacture the PC and that the Division was filled with very capable people. The problem lay embedded within IBM's established organisational structure and routines (Nelson and Winter, 1982), which proved unable to generate a product significantly different from their main product line of large, complex computing systems. Cary instead opted to construct a new organisational entity that could develop the routines and practices more specific to the technological needs and demands of the new product like the personal computer. In May 1980, he contacted Don Estridge, a project manager in the computer services division, and instructed him to coordinate and oversee a new PC project. The project would be removed from the computer services division and instead would report directly to Cary. IBM's top executives were invited to attend the bimonthly meetings on the progress of the project but were not permitted to give instructions to Estridge. While the PC project was able to draw on IBM's considerable talents, it otherwise was separated from the rest of the company.

Cary ordered Estridge to introduce a product as soon as possible. Instead of developing the entire product on its own, as was IBM's standard procedure,

\footnotetext{
${ }^{10}$ Recalling the decision, he said emphatically, "People loved the Apple! Individuals could use it by themselves. The System was capturing peoples' hearts and minds". (Interview with the authors.)
} 
Estridge's team promptly lined up subcontractors for the assorted components of the PC, including Intel and Microsoft (Bresnahan and Greenstein, 1999). Parts were purchased and assembled in Boca Raton, Florida, and in August 1981, only fifteen months after the project began, the IBM PC was introduced. Sales skyrocketed and the PC standard was set for the foreseeable future. ${ }^{11}$

As is well known, however, the story does not end there. After demand for the IBM PC overwhelmed the Boca Raton project, IBM executives decided to reincorporate the PC into its Computing Systems Division. ${ }^{12}$ The logic was that the Division's resources would enable it and the other PC manufacturers that IBM was contracting with to critically capture scale economies. But instead, this move curtailed the product's success for reasons that were more organisational in nature. While certain elements in the Division wanted to reengineer the product, other managers thought the low-margin product was unworthy to be part of the traditionally high-margin IBM product lines of mainframes and, to a lesser extent, minicomputers. Other divisions also feared that their products would be cannibalised by this nascent product. IBM continued to produce PCs, but the new technological architecture never received the requisite attention and priority to advance development into subsequent product generations within the Computing Systems Division. The dissention stalled IBM's leadership in development and production of PCs, allowing other companies to make significant advances instead. Microsoft and Intel pursued component development, while several PC clone manufacturers, including Dell, Digital, Compaq, Hewlett Packard and others, commandeered the manufacturing market. The rest is Wintel history (Bresnahan, 1998, 1999; Bresnahan and Greenstein, 1999). ${ }^{13}$

The history of the IBM story is illustrative of the difficulties and vulnerabilities of pursuing new technologies within a single organisational infrastructure. IBM's pre-existing organisational structure and routines failed to properly meet the requirements for the new $\mathrm{PC}$ technological paradigm. These routines were specially designed for complexly engineered high-margin product platforms, such as mainframes, and were neither effective nor appropriate for the new and very

\footnotetext{
${ }^{11}$ See Bresnahan (1999) for more discussion on this.

${ }^{12}$ These were successors to Cary, who retired as CEO on 1 January 1981, shortly before the PC's introduction.

${ }^{13}$ It may be disputed, of course, whether IBM could have advanced the component technologies as swiftly and effectively as have Microsoft and Intel. Nonetheless, Cary and other IBM managers maintain that even after subcontracting component responsibilities, IBM could have maintained PC leadership if it had pursued PC development and production with the unique organisational attention and supports it required.
} 
different PC product architecture. In response and after numerous difficulties, Cary instead instituted a new organisational structure for the PC platform where routines could evolve specifically for this emerging technological paradigm (Tushman and O'Reilly, 1996)

IBM's later failure also offers additional insights. While the PC flourished when supported by its own organisational structure and particular routines, it floundered when reintroduced into the company's previous infrastructure. Meanwhile, the openness of the separate venture allowed component manufacturers (especially Intel and Microsoft) to capture the lion's share of economic rents. IBM's experience illustrates that it is difficult to reincorporate a new entity into an organisation that is built on routines that support different technological paradigms. Progress is likely to stagnate upon reincorporation, and meanwhile new technological capabilities may spillover and escape to other entities. IBM's PC story had these costly disappointments follow its initial success.

\section{Kodak - Joint ventures and acquisitions in pursuit of digital imaging}

Kodak has long enjoyed global leadership in imaging, but it had begun to fear that digital technologies might prove disruptive and threaten the company's core chemical processing business. Such concerns motivated the board to lure George Fisher, fresh from Motorola's rapidly changing high-technology industries, to become Kodak's new CEO. Before ambitiously pursuing new technologies, Fisher first identified Kodak's core competencies. He introduced the mantra, "Our business is pictures, not technology", emphasising that while the company understood the consumer imaging market, it was lacking in its technological capabilities. Digital technology was already prominent in several high-margin markets. While a popular dominant design for consumer digital imaging had yet to take hold, Fisher conceded that Kodak was too far behind and ill-suited to develop and pursue digital technologies on its own.

After Fisher's arrival, Kodak began to pursue a two-tier strategy. One component sought to purchase other companies that have already developed successful digital products. For example, Kodak in August, 1998 announced its purchase of the Imation Corporation's medical imaging business. ${ }^{14}$ The purchase aimed to acquire Imation's capabilities in dry laser imaging, a hybrid of film and digital technology used for medical imaging. While Kodak at the time served approximately 30 percent of the world's medical imaging market, company sales

14“"Kodak Buying Medical Imaging Operation”. New York Times, 4 August 1998. 
chiefly relied on conventional film technology and it had yet to capture the highend digital imaging market. The purchase was described as an effort to pursue emerging markets with demands for the new technologies.

A second, and arguably more daring, component aimed at capturing a potential consumer market for digital imaging. Here, Kodak had looked to acquire digital capabilities through joint ventures with other companies. A specific initiative about which George Fisher boasted proudly was a joint venture with Intel designed to develop affordable digital pictures from standard chemical film, including the "Picture CD". Willy Shih, president of Kodak's Digital and Applied Imaging Division and director of the Picture CD project, recounted that the joint project was initially inserted into the company's main organisation, but it then promptly suffered due to the bureaucracy of Kodak. Meetings scheduled to discuss the new product suffered from logistical constraints and invited unsolicited and unnecessary input from neighboring divisions. Shih observed that these are appropriate responses from routines accustomed to monitor developments in a stable market characterised by slowly changing technologies. However, the project's slow start highlighted that the firm's current routines and practices were not capable of developing a new technology for an uncertain, albeit rapidly emerging market. Shih responded by sheltering the joint venture from Kodak's main body of standard routines and making the joint venture organisationally independent.

Shih called the project an "infrastructural play" and kept his meetings with his Kodak team secret from other Kodak executives. With George Fisher's approval and support, Shih bypassed his usual superiors and instead reported directly to Fisher. He also bucked certain preparatory work that Kodak rules normally demand, exempted his teammates from other bureaucratic requirements, and kept the project's budget secret from standard budgetary reviews. In short, he managed to hide the project from Kodak's normal business procedures — in essence, trying to save Kodak from itself - so it could develop routines that were specific to the project's demands. Avoiding the company's standard procedures also allowed the project to proceed more quickly. The idea was originally proposed in December 1997, Shih and Intel executives signed cooperative agreements in April 1998, and the completed picture CD went to test markets in September 1998. ${ }^{15}$

\footnotetext{
${ }^{15}$ Kodak's Digital Camera experienced a similar infrastructural development. Kodak originally developed digital cameras in its Consumer Imaging Division, a long-standing division that specialises in selling traditional film and chemical photofinishing, and the company was left with unusable cameras that failed to meet technological and market demands. More recently, Kodak developed a new line of digital cameras within the separate Digital and Applied Imaging Division where the project was permitted to follow a set of routines tailored for high-tech products. Kodak now enjoys a 20 percent global market share.
} 
The Picture CD met immediate success and has enjoyed ample popularity. However, similar to IBM's early success with the PC, other Kodak divisions tried to exert their influence as the project began requiring more resources, particularly when it was in need for widespread marketing and distribution. Fearing that the mass-market mentality embodied in Kodak's traditional distribution routines did not appreciate the unique features of the Picture $\mathrm{CD}$, and more generally that project's reincorporation into Kodak's standard routines could stifle the project's progress, Shih was very deliberate while the Picture CD transitioned from an ambitious venture to an established member of Kodak's product line.

Kodak's story is unfinished, as the company continues its efforts to translate the Picture CD's early success into a broad commercial triumph. In large part, the challenge rests squarely on whether Kodak managers can reconcile the very different routines that have emerged to support the very different technologies it currently has in place. The company also faces larger challenges that will continue to threaten the core businesses. Digital technology has emerged and is at least on par with traditional film technology, and Kodak is struggling to develop or acquire the requisite capabilities necessary to compete in these markets. But, and consistent with the Motorola and IBM stories, the company's early successes followed decisions to pursue emerging markets with organisational entities outside of the company's main operations. Nothing would have been gained by demanding that the company's existing organisational structure and routines operate in technological paradigms that they were not designed for. Managers instead opted to nurture creative joint ventures under separate operational rules and to purchase companies with digital capabilities. This organisational strategy enabled the development of new technologies, the pursuit of unfamiliar cooperative projects with new industry partners, and the leveraging of lessons obtained from external sources. One of the company's remaining challenges is to develop organisational routines that are specifically tailored for the emergence of digital technology. While its main business will likely remain in pictures, its picture mediums must change with rapid technological progress.

\section{Lessons Learned and Future Research}

While examining the above case studies allows for close attention to particular stories, any investigation that is limited to three firms can yield only moderate conclusions. Nonetheless, the case studies are sufficiently rich to allow for certain observations to be drawn and commonalities to be made, as well as to point to several promising areas for future research. In this section, we continue the inductive approach towards the three case studies by observing several stylised patterns within each organisation's approach to its competitive threat (Cooper 
and Schendel, 1976). The case studies constitute preliminary evidence and serve as a first step towards developing more generalisable conclusions.

\section{Success and failures in instituting new organisational entities}

One main finding across each the case studies is that the successful development of new technological paradigms often requires new and different routines (Nelson and Winter, 1982). Furthermore, accommodating to the demands of disruptive innovation often requires instituting new organisational entities that lie outside of the control of the other (competing) organisations that exist within the firm. The case studies also reveal that instituting new routines is an extremely difficult undertaking. For example, while Motorola successfully instituted an internal venture to pursue new cellular technologies, it failed to recognise the potential of digital technologies. This is particularly striking because emerging digital technologies posed an organisational challenge remarkably similar to the rise of cellular technologies. In both of the emerging technologies, the standard approach of the organisation was to remain committed to current product designs, yet in only the first instance did the company manage to institute a successful organisational strategy. It appears that past successes do not signal repeat successes.

A second difficulty confronting the implementation of new routines is that a successful organisational strategy does not necessarily translate into success in an emerging market. For example, despite IBM's early success in developing the $\mathrm{PC}$, failure to successfully incorporate the $\mathrm{PC}$ project into the existing infrastructure prevented the company from maintaining leadership in the lucrative PC market. Similarly, Kodak executives worried that the company's manufacturing, distribution, and marketing operations did not appropriately handle products developed with digital technology. This is not entirely surprising, because disruptive technologies that limit the effectiveness of downstream value chain activities tend to create significant challenges for incumbent firms (Rothaermel, 2001; Teece, 1992). While pursuing new technologies invites one set of organisational challenges, negotiating a balance between new and old routines, as well as internal and external resources, brings a second set of challenges (Tushman and O'Reilly, 1996).

Finally, many new organisational entities can prove to be fruitless by either turning into unprofitable drags or perhaps failing even to develop new products and technologies. Kodak's pursuit of digital imaging has included other efforts (not discussed here) that employed the same organisational strategies to develop new products, but these projects did not translate new technologies into lucrative applications. IBM's and Motorola's histories are similarly laced with organisational initiatives that ended in failure. The obvious response to this observation, however, 
is that the costs of several failures are easily compensated by one single success. ${ }^{16}$ This is particularly true for those industries where a successful product defines the subsequent technological paradigm and establishes the dominant design (Anderson and Tushman, 1990). Consequently, the frequency of failure should not deter continued applications of this organisational strategy towards capturing new technologies. ${ }^{17}$ The more important observation - and one that the case studies reveal in detail — is that a stubborn loyalty to well-established routines will predictably fail. Instituting new routines may be the best chance for an organisation to successfully develop and introduce new technologies even if they have a small chance of success. In summary, while new routines may be the best of all possible strategies to respond to architectural innovation, they do not guarantee success. They are difficult to institute and difficult to administer successfully.

\section{Selecting organisational strategies - A simple schema}

The case studies reveal an interesting variation in the organisational strategies each firm employed. Motorola instituted an internal venture, IBM created an internal venture that subcontracted parts from other firms - a strategy that could be labeled a hybrid between internal ventures and joint ventures, and Kodak followed a two-tier approach of purchasing companies and entering joint ventures. Each company's selection of its organisational strategy was certainly deliberate, as each organisation's managers considered alternative approaches. For example, Frank Cary weighed having the IBM team develop the PC all on its own, as was the company's custom from mainframes to minicomputers, whereas a separate IBM manager suggested purchasing a company. While the selection of a particular organisational strategy is obviously a complex decision that involves many factors, an examination of the three case studies reveals a roughly consistent logic.

The case studies reveal that one criterion in selecting a particular strategy was the nature of competition. The closer competing firms were to capturing emerging markets, the sooner the companies were required to develop new technologies.

\footnotetext{
${ }^{16}$ This argument is advanced by James McGroddy, a former Senior Vice President of IBM who directed IBM's research labs. He urges firms to continue placing "bets" on emerging technologies since the projects that succeed (and proceed to define a new technological standard) generate tremendous wealth while the failed efforts cost comparatively little. (Interviews with the authors.)

${ }^{17}$ One previous reviewer of this project noted that the case studies' success stories resemble "happy accidents". But these stories are less random if viewed in conjunction with the continued use of similar organisational initiatives. Firms continue employing this organisational strategy towards numerous projects, and a single "hit" can justify the strategy.
} 
Motorola saw opportunities to develop a new generation of wireless technology long before its competitors and began developing the cellular $800 \mathrm{MHz}$ system well before capacity constraints posed a threat to the $400 \mathrm{MHz}$ paradigm. Apple had introduced a new product generation that already disrupted the computer market, but the Apple PC had yet not fully become a new technological paradigm. IBM felt pressure to act swiftly, but a new dominant design had not yet captured the entire market, leaving the company to believe that it could still define the industry standard. Digital technology arguably disrupted Kodak's imaging market long before the company began acquiring the new technologies. While digital imaging had diffused into numerous industries, including medical and computing applications, and posed an immediate threat to supplanting chemical imaging as the new dominant design for the consumer market, Kodak knew it was far behind its new competitors.

Given the technological intensity of each of the markets examined, the time pressures are understandably significant. The widely acknowledged first-mover advantage (Lieberman and Montgomery, 1988), or the notion that market pioneers enjoy a competitive advantage over subsequent competitors, creates time-sensitive incentives for firms to be the first to market a new technology. ${ }^{18}$ The case studies reveal in turn that the firms, when selecting the appropriate organisational response, considered how much time they required to introduce a new product generation compared to their competition. Motorola, which experienced little time pressure, elected to develop the new technology internally so it would not have to share rents with other players. Alternatively, as their industries approached a new dominant design, IBM and Kodak felt pressures accumulate to develop their new products quickly and looked for partners to develop and/or acquire the necessary technologies. While time was sensitive, IBM knew it still could develop the new technology with only selected assistance and opted for a hybrid strategy that fused the elements of an internal venture and a joint venture. Kodak, under greater time pressures and lacking the time to develop the new technologies itself, opted to enter joint ventures and purchase other companies to acquire the requisite capabilities promptly. ${ }^{19}$ Accessing external sources of information, not surprisingly, becomes more important the greater the time constraints.

\footnotetext{
${ }^{18}$ The Motorola case study offers a prime example of the importance of first-mover advantage. Motorola's early introduction of cellular products allowed the company to define the industry standard, opening the market to its wireless products and positioning it as an industry leader for several subsequent years.

${ }^{19}$ One common hazard in purchasing other companies, however, is the frequency that skilled employees, and tacit knowledge, leave the company shortly after it is purchased.
} 
The pattern that emerges has firms selecting organisational strategies that are optimal for their particular location in the innovation cycle. Figure 1 models the beginning of an innovation cycle — the era of ferment - as a time path that begins after the introduction of a new technology and ends when the market settles on a dominant design (Anderson and Tushman, 1990). The case studies reveal that as the time path proceeds towards the dominant design, pressures to respond to the disruptive innovation and acquire the requisite technologies accumulate. Accordingly, firms located at points (a), (b) and (c) in Fig. 1 sense different time pressures and will likely pursue new technologies with different organisational strategies. Firms are likely to institute an internal venture if a new dominant design is not imminent (a), whereas firms will opt to leverage external sources of information through either the purchase of organisations if a new technological paradigm is close to settling on a dominant design (c) or joint venture under intermediate circumstances (b).

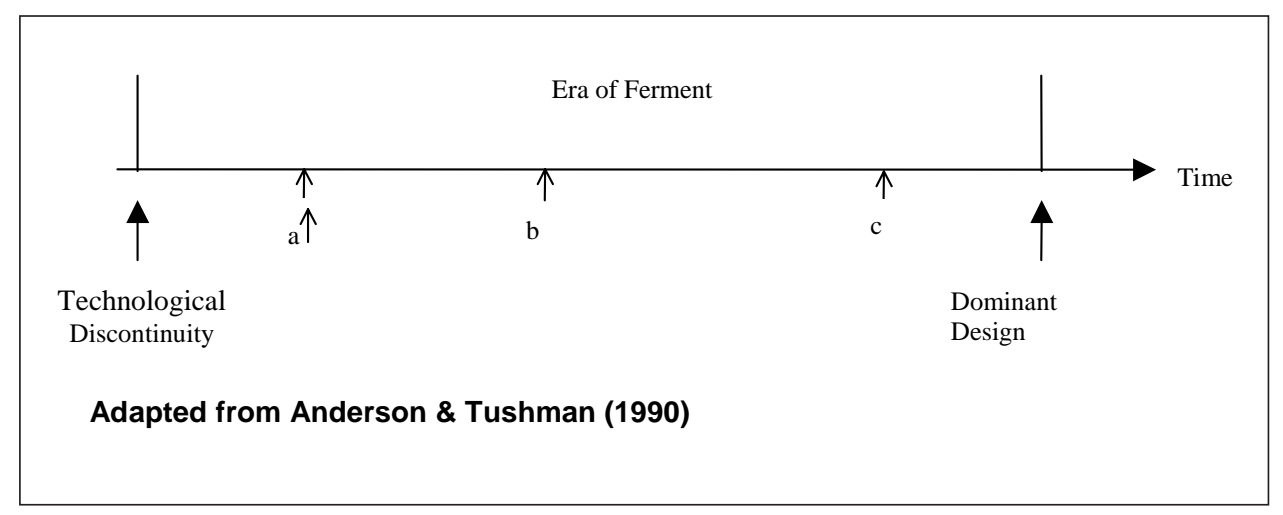

Fig. 1. Disruptive innovation and organisational response.

The above is an attempt to draw broader lessons from the case studies and to discriminate between alternative organisational strategies. Certainly, many other factors contribute to the selection of a particular technology strategy (Schilling and Hill, 1998). Nevertheless, this simple schema is supported by the case studies presented and does offer some interesting opportunities for future research. Furthermore, it is broadly consistent with the framework that different organisational arrangements are critical for profiting from technological change (Teece, 1986), as well as the argument that mergers, acquisitions and divestitures are strategic choices that compete for approaches to firm innovation (Hitt et al., 1996; Roberts and Berry, 1985). 


\section{Normative implications - Organisational strategy}

While the case studies present individual stories of successful accommodations to disruptive innovation in innovation-intense industries, they indicate that organisational responses are frequently difficult and sometimes unsuccessful. One such requirement is the development of mechanisms that allow firms to constantly and consistently adapt to frequent architectural innovations. In essence, these mechanisms represent higher-order routines that facilitate the creation and implementation of new routines to develop and adjust to new technologies. These higher-order routines, with appropriate organisational and incentive structures in place, would allow firms to simultaneously manage incremental innovation while recognising and adapting to discontinuous innovation (Tushman and O'Reilly, 1996).

If one were to advance the proposition that effective responses to disruptive innovation requires organisational change, then constant adaptation would require constant organisational change. Alternatively, depending on the time dimension of the new technology and product, many of these approaches are likely to require accessing knowledge external to the firm. In other words, successful firms in innovation-intensive industries - firms that have maintained industry leadership throughout innovation cycles - are likely to have developed routines specifically designed either to institute organisational change or to promptly acquire newly required organisational capabilities from external sources.

The case studies provide some suggestive evidence for how firms may institute routines for organisational change. For example, Motorola harbored some research laboratories in its Corporate Division, hidden from the product divisions that were most committed to current product lines and stable technological paradigms. Similarly, both IBM and Kodak provided executives with the resources to create new divisions or new infrastructures to pursue new projects, which enabled the pursuit of discontinuous technologies. In total, however, this constitutes little evidence that the firms employ firmly established routines to institute or acquire new organisational entities. Consequently, the case studies also serve as an important warning for firms on the importance of preparing for and instituting organisational change and offer few specific normative instructions as to how firms should continually undergo such organisational reform.

Nevertheless, one clear lesson that emerges is that responding to any disruptive innovation requires a clear and consistent technology strategy to be in place. Such a strategy identifies, develops and nurtures technologies that will or appear to be critical for the long run competitiveness of the company (Schilling and Hill, 1998). Such a strategy not only articulates the strategic and technological intent of the company, but also organises the company's R\&D portfolio to confront any 
limitations, identify potentially breakthrough projects, and obtain the required complementary assets (Wheelwright and Clark, 1992). Technology strategy requires organisational abilities to manage multi-technology corporations (Grandstrand and Sjolander, 1990) through the implementation of distinct organisational architectures, multiple organisational cultures and ambidextrous managers (Tushman and O'Reilly, 1996).

The histories of other companies may also offer insights into how firms nurture emerging technologies with new and unique organisational strategies. For instance, one strategy pursued by Xerox and others is to develop research parks that can more freely search for emerging technologies in emerging markets. Once new innovations are discovered, managers are free to pursue their development outside the firm's well-established organisational structure. Still another strategy is to make greater use of lead users in identifying new technologies and developing customer needs (Von Hippel et al., 1998), an approach pursued by 3M and others. One other strategy, pursued by Intel and others, is to assemble venture capital "start-up" funds that invest within the industry to identify new opportunities. These efforts are designed to search systematically for new technologies as they develop. A final effort, instituted by Kodak under George Fisher, is to assemble "search committees" that consist of the company's top researchers and are assigned to identify and nurture new technologies in separate projects. These committees, which often report directly to the CEO, can remain removed from the firm's embedded routines and can thus freely pursue new opportunities. All of these projects are efforts to develop mechanisms that can pursue new technologies and avoid the obstacles often created by inflexible routines.

The presence of these more organisational approaches illustrates two conclusions. The first, stemming from the large number of efforts that these different firms make, is that firms must take the threat of disruptive innovation seriously. The difficulties in responding to such innovations must be understood and mechanisms that can systematically handle organisational change must be put in place. The second conclusion is illustrated by the broad diversity of approaches. There appears to be no "best practice" for how to respond to disruptive innovation. Firms must instead sample from a wide variety of systematic efforts and then use the most appropriate to create flexibility for emerging technologies (Thomke and Reinertsen, 1998).

\section{Conclusion}

This paper seeks to understand how incumbent firms organise in the face of technological discontinuity. Building on seminal models that observe how organisational structures and routines for one technological paradigm often fail 
to be effective in subsequent paradigms, we observe that some incumbent firms have successfully pursued new technologies when they create new organisational entities that enable the pursuit of unfamiliar technologies or facilitate the gathering of external sources of knowledge. Three case studies are presented that identify a particular effectiveness in pursuing new technologies by abandoning wellestablished routines and constructing new organisational entities. The case studies further indicate that instituting new routines is a difficult undertaking, highlighting the fact that firms will continue to struggle when adapting to disruptive innovation. Lastly, they illustrate that although each firm employed different organisational approaches, a simple pattern emerges which suggests that certain organisational strategies are more appropriate for particular stages of the innovation cycle.

The methodology of relying on case studies is necessarily limited, and this analysis does not attempt to provide ambitious answers to the widely recurring phenomena of entrant-incumbent dynamics and leadership displacement. It instead takes an inductive approach, examining particular firms that are roughly representative of other successful firms threatened by entrants with emerging technologies, and it observes some important commonalties in the organisational strategies that the firms employed. These similarities may not be widely generalisable across firms and industries, but they do offer some interesting lessons. Understanding how some firms moved beyond the limitations of their well-established organisational structure and routines by accessing external sources, and appreciating the alternative organisational strategies they employed, offers important lessons for understanding entrant-incumbent dynamics.

\section{Acknowledgements}

We would like to thank the Berkeley Roundtable on the International Economy (BRIE) for its generous support and assistance throughout the development of this study. We are particularly indebted to James McGroddy, Michael Borrus, and John Zysman. We would also like to thank the Institute of Management, Innovation, and Organisation (IMIO) for its support. We appreciate the helpful comments of Kyle Mayer, Deepak Somaya, David Mowery, and David Teece. Sincere appreciation goes to the current and former executives at Motorola, IBM, and Kodak whose time made this project possible. All errors and omissions are our own.

\section{References}

Abernathy, WJ (1978). The Productivity Dilemma. Baltimore: John Hopkins University Press. 
Abernathy, WJ and JM Utterback (1978). Patterns of industrial innovation. Technology Review, June/July, 41-47.

Ahuja, G and CM Lampert (2001). Entrepreneurship in the large corporation: A longitudinal study of how established firms create breakthrough discoveries. Administrative Science Quarterly, 38, 51-73.

Amburgey, T, D Kelly and W Barnett (1993). Resetting the clock: The dynamics of organizational change and failure. Administrative Science Quarterly, 38, 51-73.

Anderson, P and ML Tushman (1990). Technological discontinuities and dominant designs: A cyclical model of technological change. Administrative Science Quarterly, 35, 604-633.

Bresnahan, TF (1998). New modes of competition and the future structure of the computer industry. In Competition, Convergence, and the Microsoft Monopoly. New York: Kluwer Press.

Bresnahan, TF (1999). Computing. In U.S. Industry in 2000: Studies in Competitive Performance, DC Mowery (ed.). Washington, DC: National Academy Press.

Bresnahan, TF and S Greenstein (1999). Technological competition and the structure of the computer industry. Journal of Industrial Economics, 47(1), 1-40.

Christensen, CM (1997). The Innovator's Dilemma: When New Technologies Cause Great Firms to Fail. Boston, MA: Harvard Business School Press.

Christensen, CM and RS Rosenbloom (1995). Explaining the attacker's advantage: Technological paradigms, organizational dynamics and the value network. Research Policy, 24, 233-257.

Cohen, WM and DA Levinthal (1990). Absorptive capacity: A new perspective on learning and innovation. Administrative Science Quarterly, 35(1), 128-152.

Cooper, AC and D Schendel (1976). Strategic responses to technological threats. Business Horizons, February, 61-69.

Dosi, G (1988). The nature of the innovative process. In Technical Change and Economic Theory, G Dosi, C Freeman, Richard Nelson, G Silverberg and L Soete (eds.). New York: Pinter Publishers.

Dougherty, D (1992). Interpretive barriers to successful product innovation in large firms. Organization Science, 3( 2), 179-202.

Dougherty, D and C Hardy (1996). Sustained product innovation in large, mature organizations: Overcoming innovation-to-organization problems. Academy of Management Journal, 39(5), 1120-1153.

Dougherty, D and T Heller (1994). The illegitimacy of successful product innovation in established firms. Organization Science, 5(2), 200-218.

Foster, RN (1986). Innovation: The Attacker's Advantage. New York: Summit Books.

Grandstrand, O and S Sjolander (1990). Managing innovation in multi-technology corporations. Research Policy, 19, 1, 35-60.

Hannan, MT and J Freeman (1984). Structural inertia and organizational change. American Sociological Review, 49, 2, 149-164.

Henderson, RM and K Clark (1990). Architectural innovation: The reconfiguration of existing product technologies and the failure of established firms. Administrative Science Quarterly, 35, 9-30. 
Hill, CW and FT Rothaermel (2003). The performance of incumbent firms in the face of radical technological innovation. Academy of Management Review, 28(2), 257-274.

Hitt, MA, RE Hoskisson, RA Johnson and DD Moesel (1996). The market for corporate control and firm innovation. Academy of Management Journal, 39(5), 1084-1119.

Kogut, B (1988). Joint ventures: Theoretical and empirical perspectives. Strategic Management Journal, 9( 4), 319-332.

Leonard-Barton, D (1992). Core capabilities and core rigidities: A paradox in managing new product development. Strategic Management Journal, 13, 111-125.

Levitt, B and JG March (1988). Organizational learning. Annual Review of Sociology, 14, 319-340.

Lieberman, MB and D Montgomery (1988). First-mover advantages. Strategic Management Journal, 9(5), 41-58.

Methe, DT, A Swaminathan, W Mitchell and R Toyama (1997). The underemphasized role of diversifying entrants and industry incumbents as the sources of major innovations. In Strategy Discovery: Competiting in New Areas, H Thomas and D O'Neal (eds.). New York: Wiley.

Miller, DJ (1993). The architecture of simplicity. Academy of Management Review, 18, $116-137$.

Nelson, RR and SG Winter (1982). An Evolutionary Theory of Economic Change. Cambridge: Belknap Press.

Pisano, GP (1997). The Development Factory: Unlocking the Potential of Process Innovation. Boston: Harvard Business School Press.

Roberts, EB and CA Berry (1985). Entering new businesses: Selecting strategies for success. Sloan Management Review, 26, 3-17.

Rosenbloom, RS and CS Christensen (1998). Technological discontinuities, organizational capabilities, and strategic commitments. In Technology, Organization, and Competitiveness: Perspectives On Industrial and Corporate Change, G Dosi, DJ Teece and J Chytry (eds.). New York: Oxford University Press.

Rothaermel, FT (2001). Incumbent's advantage through exploiting complementary assets via interfirm cooperation. Strategic Management Journal, 22, 687-699.

Schilling, MA and CWL Hill (1998). Managing the new product development process: Strategic imperatives. Academy of Management Executive, 12(3), 67-81.

Teece, DJ (1986). Profiting from technological innovation: Implications for integration, collaboration, licensing and public policy. Research Policy, 15(6), 285-305.

Teece, DJ (1992). Competition, cooperation, and innovation: Organizational arrangements for regimes of rapid technological progress. Journal of Economic Behavior and Organization, 18, 1-25.

Thomke, S and D Reinertsen (1998). Agile product development: Managing development flexibility in uncertain environments. California Management Review, 41(1), 8-30.

Tushman, ML and P Anderson (1986). Technological discontinuities and organizational environments. Administrative Science Quarterly, 31, 439-465.

Tushman, ML and CA O'Reilly (1996). Ambidextrous organizations: Managing evolutionary and revolutionary change. California Management Review, 38(4), 8-30. 
Von Hippel, E, J Churchill and M Sonnack (1998). Breakthrough Products and Services with Lead User Research. Cambridge, MA: Oxford University Press.

Wheelwright, SC and KB Clark (1992). Creating project plans to focus product development. Harvard Business Review, 70(2), 70-82. 